\title{
Acetylcholine Synthesis and Release following Continuous Intracerebral Administration of NGF in Adult and Aged Fischer-344 Rats
}

\author{
R. J. Rylett, ${ }^{1,2}$ S. Goddard, ${ }^{1}$ B. M. Schmidt, ${ }^{1}$ and L. R. Williams ${ }^{3, a}$ \\ ${ }^{1}$ Department of Physiology, Universily of Weslern Onlario, London, Ontario, Canada N6A 5C1, ${ }^{2}$ The J. P. Robarts \\ Research Institute, London, Ontario, Canada N6A 5K8, and ${ }^{3} \mathrm{CNS}$ Diseases Research Unit, The Upjohn Company, \\ Kalamazoo, Michigan 49001
}

NGF promotes the survival and enhances the neurotransmitter phenotype of basal forebrain and striatal cholinergic neurons in brain of rat. The objective of the present study was to determine whether stimulations of the cholinergic neuronal markers ChAT and high-affinity choline uptake are reflected in enhanced synthesis and release of $A C h$. Enhancement of $\mathrm{ACh}$ release in brain of adult and aged rats could result in increased cholinergic neurotransmission, and altered animal behavior. NGF $(1.2 \mu \mathrm{g} / \mathrm{d})$ was administered intracerebroventricularly for 2 weeks by osmotic minipump to male Fischer-344 rats aged 4 and 24 months. Cholinergic neuronal functional parameters were measured in frontal cortex, hippocampus, and striatum. In young adult rats, increased ChAT and choline uptake activities were accompanied by enhanced $\mathrm{ACh}$ synthesis, basal and depolarization-induced release of both endogenous and newly synthesized transmitter, with the largest effect generally being observed in striatum. In aged animals, the responses to NGF were less uniform. Whereas the pattern for changes in ChAT activity was similar to that seen in younger animals, choline uptake activity was increased only in frontal cortex and striatum. Coincidentally, $A C h$ synthesis was also increased only in these two brain regions. ACh content of synaptosomes was not affected by age or NGF treatment, and the ACh levels in microwaved samples of striatum and basal forebrain were not affected by NGF treatment. However, profound deficits in both basal and evoked release of newly synthesized ACh were observed in the aged rats. NGF treatment had no significant effect on the basal release of newly synthesized $\mathrm{ACh}$ in aged rats. Treatment enhanced depolarization-induced release of both newly synthesized and endogenous transmitter in hippocampus and striatum, but not in frontal cortex. Although this release was increased up to $50 \%$ compared to aged-matched controls, the levels achieved were still only $\mathbf{4 0} \%$ of those observed in the normal adult controls.

[Key words: NGF, ACh, aging, Fischer-344, cholinergic, ChAT, high-affinity choline transport, chronic administration]

\footnotetext{
Received Oct. 15, 1992; revised Feb. 25, 1993; accepted Mar. 30, 1993.

We thank Ms Katherine Hanna and Mrs. Wanda Davis for technical assistance. This research was supported by grants from the Medical Research Council of Canada and The Upjohn Company through the London-Upjohn Neuroscience Program to R.J.R.

Correspondence should be addressed to Dr. Rebecca Jane Rylett, Department of Physiology, Medical Sciences Building, University of Western Ontario, London, Ontario, Canada N6A 5C1.

Present address: AMGEN, Thousand Oaks, CA 91320.

Copyright (C) 1993 Society for Neuroscience $0270-6474 / 93 / 133956-08 \$ 05.00 / 0$
}

NGF promotes differentiation, survival, and expression of neurotransmitter phenotype of sympathetic and sensory neurons in the PNS (Levi-Montalcini, 1982) and forebrain cholinergic neurons in the CNS (Whittemore and Seiger, 1987; Hefti et al., 1989; Lapchak et al., 1993). It has been hypothesized that some degenerative neurologic disorders, including Alzheimer's disease, could be due to a deficiency in endogenously produced trophic factors or to decreased responsiveness of neuronal populations to these agents (Appel, 1981; Hefti and Weiner, 1986). This has led to speculation that neurotrophic factors may eventually be used to treat some neurodegenerative disorders either by direct local administration, by pharmacological modification of the synthesis in vivo, or by release from genetically engineered transplanted cells (Lapchak et al., 1993).

In both in vitro and in vivo models, NGF enhances cholinergic neuronal markers in basal forcbrain and striatal ncurons. NGF increases ChAT (acetyl-CoA:choline- $O$-acetyltransferase; EC2.3.1.6) specific activity in basal forebrain (Gnahn et al., 1983) and striatum (Mobley et al., 1985) in brain of neonatal rats. Studies that have used cultured neurons as a model have also observed increases in ChAT activity (Honneggar and Lenoir, 1982; Hefti et al., 1985). Importantly, intracerebral administration of NGF prevents retrograde degeneration of septal cholinergic neurons and promotes repair following partial or complete fimbrial lesion when given immediately following or within a few weeks after injury (Hefti, 1986; Williams et al., 1986; Hagg et al., 1988), and improves performance of aged rats on spatial memory tasks (Fischer et al., 1987). We have demonstrated recently that cholinergic neurons in unlesioned brain of both adult and aged rats respond to chronic administration of exogenous NGF with increases in high-affinity choline transport, the presumed rate-limiting step for ACh synthesis (Jope, 1979), as well as with increased ChAT activity (Williams and Rylett, 1990).

An important question that requires attention is whether the increased cholinergic neuronal markers, most frequently ChAT, that have been measured in response to NGF administration in vivo and in vitro are reflected in enhanced $\mathrm{ACh}$ synthesis and release, and increased cholinergic transmission in brain. In cholinergic neurons in culture, both increased $\mathrm{ACh}$ content and release have been measured following incubation of basal forebrain neurons with NGF (Takei et al., 1988, 1989), but little is known about the effect of chronic in vivo administration of NGF on these measures, in particular in the unlesioned adult and aging brain. Kewitz et al. (1990) reported transient elevations in $\mathrm{ACh}$ concentration in brains of neonatal rats injected with single high doses of NGF, but important differences may exist 
between NGF production and responsiveness in newborn brain compared to the adult or aged. Recently, Lapchak and Hefti (1991) demonstrated that intraventricular administration of human recombinant NGF partially protected against degeneration of lesioned septohippocampal cholinergic neurons in adult rats with partial maintenance of ${ }^{3} \mathrm{H}$-ACh synthesis and release. The objective of the present study was to determine whether ACh synthesis and release from basal forebrain and striatal cholinergic neurons, measured ex vivo, were altered following chronic intracerebroventricular administration of exogenous NGF for 2 weeks to brain of young adult and aged Fischer- 344 male rats.

\section{Materials and Methods}

\section{Materials}

Male Fischer-344 rats, 4 and 24 months of age, were obtained from National Institutes on Aging colony at Harlan/Sprague-Dawley (Indianapolis, IN). Alzet osmotic minipumps, model 2002, were supplied by Alza Corp. (Palo Alto, CA). Renin-free $2.5 \mathrm{~S}$ mouse NGF was obtained from Bioproducts for Science (Indianapolis, IN). Choline iodide, hemicholinium-3, globulin-free crystalline bovine serum albumin, Tris base, eserine sulfate, rat serum albumin, luminol, choline oxidase, peroxidase, acetylcholinesterase, choline kinase, ATP, sodium tetraphenylboron, glycylglycine buffer, acetylcholine chloride, dithiothreitol, and cysteine were purchased from Sigma Chemical Co. (St. Louis, MO). ${ }^{3} \mathrm{H}-$ choline chloride $(80 \mathrm{Ci} / \mathrm{mmol})$ was from Amersham Radiochemical Corp. (Oakville, Ontario, Canada). ${ }^{14} \mathrm{C}$-acetylcoenzyme A $(58 \mathrm{mCi} / \mathrm{mmol})$ and HEPES were obtained from ICN. $\gamma^{32}$ P-ATP $(10 \mathrm{Ci} / \mathrm{mmol})$ was purchased from Du Pont-New England Nuclear (Mississauga, Ontario, Canada). Acetylcoenzyme A (lithium salt) was purchased from Boehringer-Mannheim. 3-Heptanone was from Aldrich Chemical Co. Intracerebral infusion cannulas were purchased from Plastics One (Roanoke, VA).

\section{Animal care}

Animals were housed with a daily photoperiod of $12 \mathrm{hr}$ of light between 0600 and $1800 \mathrm{hr}\left(22^{\circ} \mathrm{C}\right)$, and free access to water and food. Anesthesia for surgery was induced by intramuscular injection of a mixture of ketamine ( $4 \mathrm{mg} / \mathrm{ml}$ ), xylazine (Rompun; $1.3 \mathrm{mg} / \mathrm{ml}$ ), and acepromazine $(0.25 \mathrm{mg} / \mathrm{ml})$. Animals were 4 and 24 months of age at the time of cannula implantation and start of vehicle or NGF infusion.

\section{$N G F$ preparation and administration}

The concentration of pure NGF in a stock solution of PBS was determined by molar extinction $\left(1.64 \mathrm{OD}_{280} / \mathrm{mg} / \mathrm{ml}\right)$, and aliquots of $1 \mathrm{mg}$ / $\mathrm{ml}$ were stored at $-70^{\circ} \mathrm{C}$ until use. Working solutions were prepared at the time of surgery by dilution in Dulbecco's phosphate-buffered saline containing $0.1 \%$ rat serum albumin; this diluent also served as vehicle in the vehicle-infused animals with albumin at $1 \mathrm{mg} / \mathrm{ml}$ added as a nonspecific protein. Drug infusion cannulas were constructed and implanted at $1.2 \mathrm{~mm}$ lateral to bregma into the right lateral ventricle using a procedure modified from Williams et al. (1987). Alzet osmotic pumps were used to deliver sterile NGF or vehicle solutions for 2 weeks; the NGF dose of $1.2 \mu \mathrm{g} / \mathrm{d}$ was found previously to stimulate basal forebrain ChAT activity maximally in axotomized young adult Sprague-Dawley female rats (Williams et al., 1989).

\section{Assay of cholinergic functional parameters}

Cholinergic neurochemical function was investigated through measurement of (1) synthesis of ${ }^{3} \mathrm{H}$-ACh, (2) release of newly synthesized ${ }^{3} \mathrm{H}$ $\mathrm{ACh},(3)$ release of endogenous $\mathrm{ACh},(4)$ high-affinity choline uptake activity, (5) ChAT activity, and (6) content of ACh in brain areas and nerve terminal preparations.

Synthesis of acetylcholine and ${ }^{3} \mathrm{H}$-choline uptake. Capacity for synthesis of ${ }^{3} \mathrm{H}$-ACh was measured in synaptosomes incubated with ${ }^{3} \mathrm{H}$ choline. Synaptosomes from hippocampus, frontal cortex, and striatum of right hemisphere were prepared according to the procedure of Gray and Whittaker (1962); an aliquot of the total homogenate was removed for assay of ChAT activity, frozen on dry ice, and stored at $-80^{\circ} \mathrm{C}$ (see methods below). Nerve terminals were resuspended in cold HEPES- buffered Krebs-Ringer solution (in mM: $\mathrm{NaCl}, 124 ; \mathrm{KCl}, 5 ; \mathrm{CaCl}_{2}, 1.5$; $\mathrm{MgCl}_{2}, 1.3$; HEPES-NaOH, pH 7.4, 20; glucose, 10) to yield the crude synaptosome suspension; of this suspension, an aliquot was removed for mcasurcment of synaptosomal ACh content (see methods below) Aliquots of synaptosomal suspensions were equilibrated to $37^{\circ} \mathrm{C}$, and then incubated in the presence of $0.5 \mu \mathrm{M}{ }^{3} \mathrm{H}$-choline for $5 \mathrm{~min}$ to allow the formation of ${ }^{3} \mathrm{H}-\mathrm{ACh}$; hemicholinium-3 $(10 \mu \mathrm{M})$ was added to some aliquots to allow determination of hemicholinium-insensitive choline accumulation as correction for background. At the end of the incubation, synaptosomes were collected by centrifugation, and then washed to remove excess tritium. Portions of the washed radiolabeled synaptosome samples were removed for determination of release of newly synthesized ${ }^{3} \mathrm{H}-\mathrm{ACh}$ (see methods below).

Following the final wash, synaptosomes were lysed by the addition of $5 \%$ trichloroacetic acid (TCA) for the extraction and measurement of tritiated choline metabolite content and ${ }^{3} \mathrm{H}-\mathrm{ACh}$ synthesis. Following centrifugation, an aliquot was removed from each sample for determination of ${ }^{3} \mathrm{I}$-choline uptake into nerve terminals. The remaining supernatants were shaken with water-saturated diethyl ether to remove TCA, and then extracted with sodium tetraphenylboron in 3-heptanone to isolate choline esters in the organic phase. An aliquot of the organic phase was back-extracted with $0.4 \mathrm{~N} \mathrm{HCl}$, and the resulting aqueous phase, now containing tritiated choline and $\mathrm{ACh}$, was reduced to dryness in vacuo.

${ }^{3} \mathrm{H}$-choline and ${ }^{3} \mathrm{H}-\mathrm{ACh}$ were separated and quantified following enzymatic conversion of ${ }^{3} \mathrm{H}$-choline to ${ }^{3} \mathrm{H}$-phosphorylcholine, using a modification of the method of Goldberg and McCaman (1975). To the dried samples was added $100 \mu$ l of a reaction solution composed of choline kinase, $0.2 \mathrm{U} / \mathrm{ml}$; ATP, $15.5 \mathrm{~mm}, \mathrm{MgCl}_{2}, 18.5 \mathrm{~mm}$, in $93 \mathrm{~mm}$ glycylglycine buffer, $\mathrm{pH} 8.3$. Samples were incubated for $30 \mathrm{~min}$ at $37^{\circ} \mathrm{C}$ and then extracted with sodium tetraphenylboron in 3-heptanone (10 $\mathrm{mg} / \mathrm{ml}$ ). Aliquots of the organic phase containing ${ }^{3} \mathrm{H}-\mathrm{ACh}$ and the aqueous phase containing ${ }^{3} \mathrm{H}$-choline as phosphorylcholine were added to scintillation cocktails for quantitation of tritium. Data was normalized to sample protein content measured by the method of Lowry et al. (1951), and expressed as picomoles of ${ }^{3} \mathrm{H}-\mathrm{ACh}$ or ${ }^{3} \mathrm{H}$-choline per milligram of protein.

Release of newly synthesized acethylcholine. The release of newly synthesized ACh was measured from synaptosomes following labeling of ACh pools with ${ }^{3} \mathrm{H}$-choline. Basal ${ }^{3} \mathrm{H}$-ACh release was monitored over two $10 \mathrm{~min}$ intervals, followed by $\mathrm{K}^{+}$-depolarization-evoked release of ${ }^{3} \mathrm{H}-\mathrm{ACh}$ measured over one $5 \mathrm{~min}$ interval; $\mathrm{KCl}$ was added to synaptosome samples at a final concentration of $40 \mathrm{~mm}$. Supcrnatants wcre saved following each incubation for measurement of released ${ }^{3} \mathrm{H}-\mathrm{ACh}$, as were pellets for extraction for measurement of ${ }^{3} \mathrm{H}-\mathrm{ACh}$ content and sample protein estimation.

${ }^{3} \mathrm{H}$-ACh in supernatants was separated from ${ }^{3} \mathrm{H}$-choline and measured using a separate modification of the choline kinase method of Goldberg and McCaman (1975). Of the supernatants, $300 \mu \mathrm{l}$ portions were added to $75 \mu \mathrm{l}$ of a reaction solution composed of choline kinase, $2.5 \mathrm{mU}$; ATP, $50 \mathrm{~mm}, \mathrm{MgCl}_{2}, 6.25 \mathrm{~mm}$, in $250 \mathrm{~mm}$ glycylglycine buffer, pH 8.5 . Samples were incubated at $37^{\circ} \mathrm{C}$ for $30 \mathrm{~min}$, and then $300 \mu \mathrm{l}$ of sodium tetraphenylboron in 3-heptanone $(30 \mathrm{mg} / \mathrm{ml})$ was added to extract the ${ }^{3} \mathrm{H}$-ACh. Aliquots of the organic phase containing ${ }^{3} \mathrm{H}-\mathrm{ACh}$ and aqueous phase containing ${ }^{3} \mathrm{H}$-choline as phosphorylcholine were prepared for scintillation counting. ${ }^{3} \mathrm{H}-\mathrm{ACh}$ and ${ }^{3} \mathrm{H}$-choline content remaining in the synaptosomal pellets from these samples was quantificd using the method described above for synthesis of acetylcholine.

Release of endogenous acetylcholine. Potassium-evoked release of endogenous ACh was measured from slices of hippocampus, frontal cortex and striatum ( $300 \mu \mathrm{m}$, right hemisphere) by the chemiluminescent method of Israel and Lesbats (1982). Between one and three tissue slices were placed into a cuvette containing $900 \mu \mathrm{l}$ of Krebs-Ringer bicarbonate buffer (in mM: $\mathrm{NaCl}, 132 ; \mathrm{KCl}, 5 ; \mathrm{MgCl}_{2}, 1.3 ; \mathrm{CaCl}_{2}, 1.5 ; \mathrm{NaH}_{2} \mathrm{PO}_{4}$, 1.2; $\mathrm{NaHCO}_{3}, 22$; glucose, 10 ; pH 7.4; gassed with $95 \% \mathrm{O}_{2}, 5 \% \mathrm{CO}_{2}$ ) at $37^{\circ} \mathrm{C}$ with the additions of $10 \mu \mathrm{l}$ of luminol $(5.4 \mathrm{mg} / \mathrm{ml}$ stock concentration), $30 \mu \mathrm{l}$ of peroxidase $(400 \mathrm{U} / \mathrm{ml}$ stock), $30 \mu \mathrm{l}$ of choline oxidase $(50 \mathrm{U} / \mathrm{ml}$ stock), and $30 \mu \mathrm{l}$ of acetylcholinesterase $(125 \mathrm{U} / \mathrm{ml}$ stock). Cuvettes were placed in a darkened chamber with electronic stirrer apposed to a photomultiplier tube coupled to an amplifier and chart recorder. $\Lambda$ fter a stable baseline was achicved, $\mathrm{KCl}$ was added (final concentration, $40 \mathrm{~mm}$ ), and the release of $\mathrm{ACh}$ was measured as light emitted. Each response was calibrated individually by the addition of at least four ACh standards (25-150 pmol) to the cuvette. ACh release from each slice(s) was determined from the standard curve constructed 
Table 1. Cholinergic neuronal markers in young adult and aged male Fischer-344 rats

\begin{tabular}{|c|c|c|c|c|c|c|c|}
\hline Age group & Brain area & ChAT & $\begin{array}{l}\text { High-affinity } \\
\text { choline } \\
\text { uptake }\end{array}$ & $\begin{array}{l}\text { ACh } \\
\text { synthesis }\end{array}$ & $\begin{array}{l}\text { Basal }{ }^{3} \mathrm{H}-\mathrm{ACh} \\
\text { release }\end{array}$ & $\begin{array}{l}\text { Evoked }{ }^{3} \mathrm{H}-\mathrm{ACh} \\
\text { release }\end{array}$ & $\begin{array}{l}\text { Endogenous } \\
\text { ACh release }\end{array}$ \\
\hline \multirow{3}{*}{4 month } & Cortex & $40.0 \pm 2.8$ & $6.1 \pm 0.5$ & $4.1 \pm 0.2$ & $73.4 \pm 6.6$ & $258.1 \pm 19.2$ & $124.0 \pm 7.4$ \\
\hline & Hippocampus & $47.6 \pm 2.5$ & $12.3 \pm 0.7$ & $7.6 \pm 0.2$ & $115.4 \pm 6.6$ & $441.9 \pm 20.8$ & $100.9 \pm 10.2$ \\
\hline & Striatum & $164.4 \pm 4.5$ & $32.6 \pm 2.4$ & $21.1 \pm 1.2$ & $431.8 \pm 29.3$ & $849.6 \pm 61.6$ & $235.9 \pm 11.4$ \\
\hline \multirow[t]{3}{*}{24 month } & Cortex & $39.7 \pm 1.8$ & $5.3 \pm 0.5$ & $3.6 \pm 0.4$ & $26.8 \pm 2.8^{* *}$ & $77.0 \pm 10.5^{* *}$ & $112.4 \pm 11.2$ \\
\hline & Hippocampus & $49.3 \pm 2.7$ & $9.8 \pm 1.0$ & $6.7 \pm 0.7$ & $65.6 \pm 18.2^{* *}$ & $131.7 \pm 15.1^{* *}$ & $84.5 \pm 5.5$ \\
\hline & Striatum & $132.5 \pm 8.6^{*}$ & $23.7 \pm 2.1^{* *}$ & $17.5 \pm 1.7$ & $179.8 \pm 44.8^{* *}$ & $219.2 \pm 13.3^{* *}$ & $172.9 \pm 15.4^{*}$ \\
\hline
\end{tabular}

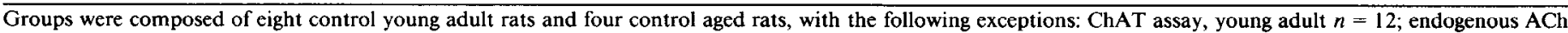

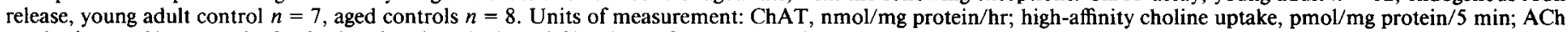

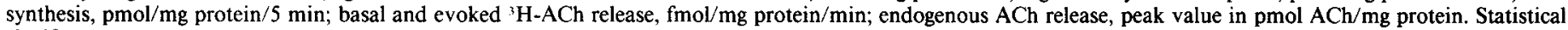
significance compared to 4 month control group determined by unpaired Student's $t$ test: ${ }^{*}, p \leq 0.05 ;{ }^{* *}, p \leq 0.01$.

from the ACh standards by linear regression, and normalized to the slice protein content.

Measurement of acetylcholine content. Neuronal ACh content was measured in synaptosomes and brain samples from vehicle-treated control and NGF-treated rats. Synaptosomes removed immediately after preparation were extracted with $5 \%$ TCA and extracted as described above for synthesis of $\mathrm{ACh}$ until and including the step for drying samples under vacuum. Brain samples obtaincd from rats killed by head-focused microwave (Gerling Moore, Palo Alto, CA) were weighed and homogenized in $1 \mathrm{M}$ formic acid/acetone $(15: 85, \mathrm{v} / \mathrm{v})$, and then centrifuged; aliquots of supernatants were reduced to dryness in vacuo.

ACh was hydrolyzed by acetylcholinesterase and converted enzymatically to ${ }^{32} \mathrm{P}$-phosphorylcholine with ${ }^{32} \mathrm{P}$-ATP, following the conversion of choline to phosphorylcholine with ATP, according to the radioenzymatic method of Goldberg and McCaman (1975). To the dried samples was added $32 \mu \mathrm{l}$ of a reaction mixture composed of ATP, 0.8 $\mathrm{mM}$; dithiothreitol, $5 \mathrm{~mm}$; $\mathrm{MgCl}_{2}, 11.5 \mathrm{~mm}$; choline kinase, $2.5 \mathrm{mU}$; in glycylglycine buffer, $50 \mathrm{~mm}, \mathrm{pH} 8.0$. Samples were incubated at $30^{\circ} \mathrm{C}$ for $25 \mathrm{~min}$ to phosphorylate choline. A second reaction mixture $(10 \mu \mathrm{l})$ composed of acetylcholinesterase, $2.5 \mathrm{U}$, and ${ }^{32} \mathrm{P}-\mathrm{ATP}, 0.5 \mu \mathrm{Ci}$, in buffer was added to hydrolyze $\mathrm{ACh}$ and allow production of ${ }^{32} \mathrm{P}$-phosphorylcholine. Incubation was continued for $20 \mathrm{~min}$, and then stopped by the addition of $100 \mu \mathrm{l}$ of cold $50 \mathrm{~mm} \mathrm{NaOH}$. ${ }^{32} \mathrm{P}$-phosphorylcholine was separated from unreacted ${ }^{32} \mathrm{P}$-ATP by pouring samples over Amberlite CG400 (formate form) columns and eluting with $50 \mathrm{~mm} \mathrm{NaOH}$. Eluents were counted for ${ }^{32} \mathrm{P}$, normalized to synaptosomal protein content or tissue weight, and expressed as picomoles of $\mathrm{ACh}$ per milligram of protein or tissue.

Choline acetyltransferase assay. ChAT activity was measured using a modification of the radioenzymatic method of Fonnum (1969), as described by Williams and Rylett (1990).

\section{Data analysis}

Assays were performed in duplicate or triplicate, with means calculated to give a single $n$ value. Data are expressed as mean \pm SEM values. Statistical analysis was by one-way ANOVA combined with Duncan's multiple-range test for post hoc analysis, or by unpaired two-tailed Student's $t$ test. The criterion set for statistical significance was $P \leq$ 0.05 .

\section{Results}

Values for measurements of cholinergic neuronal parameters in the vehicle-treated control young adult ( 4 month) and aged ( 24 month) male Fischer-344 rats are shown for comparison in Table 1. There are clear age-related decreases in several of the parameters that appear to be brain region specific. The activities of ChAT and high-affinity choline uptake and release of endogenous ACh were significantly decreased in striatum, but not in frontal cortex or hippocampus. Dramatic, 60-70\%, age-related decreases were observed in all three brain regions for both basal and evoked release of newly synthesized $\mathrm{ACh}$. ACh synthesis in aged rats did not differ from that observed in the younger animals.

\section{Effect of NGF on cholinergic neuronal phenotypic markers}

ChAT and high-affinity choline uptake appear to be expressed selectively in cholinergic neurons, and therefore can serve as phenotypic markers for these neurons. Similar to measurements made previously (Williams and Rylett, 1990), we observed that chronic intracerebral administration of NGF for 2 weeks significantly elevated ChAT-specific activity in frontal cortex, hippocampus, and striatum of both young adult and aged rats, with the largest effect appearing in the striatum (Fig. 1). High-affinity, hemicholinium-sensitive choline uptake was also significantly elevated in all three brain areas of young adult rats, as illustrated in Figure 2. In aged rats, however, synaptosomal choline uptake was significantly increased compared to age-matched controls only in striatum (increased $39 \pm 4 \%, P<0.01$ ). It was shown in the previous study (Williams and Rylett, 1990) that vehicletreatment had no effect upon ChAT or high-affinity choline transport in any of the brain regions studied in either age group.

\section{Synthesis of $A C h$}

Choline taken up into cholinergic nerve terminals by the sodium-coupled choline carrier is converted predominantly to $\mathrm{ACh}$ (Yamamura and Snyder, 1973). As the accumulation of choline by cholinergic nerve terminals appeared to be enhanced by NGF treatment, we predicted that this would be reflected as an increase in the production of the neurotransmitter. It was also of interest to determine whether age-related changes existed in the responsiveness of cholinergic neurons to NGF for this functional parameter.

Intracerebral administration of NGF for 2 weeks produced significant increases in ${ }^{3} \mathrm{H}$-ACh synthesis to about $40 \%$ of control in all three brain regions of 4-month-old rats, as shown in Figure 3. Synaptosomal ${ }^{3} \mathrm{H}-\mathrm{ACh}$ synthesis was also increased in brain of aged rats. When normalized to the young adult control group, ${ }^{3} \mathrm{H}$-ACh synthesis in the aged NGF-treated group was $115 \pm 8 \%, 100 \pm 3 \%$, and $114+7 \%$ in frontal cortex hippocampus, and striatum, respectively. Compared to the 24 month age-matched controls, this represented increases in neurotransmitter synthesis of $38 \pm 8 \%(P<0.05)$ and $33 \pm 10 \%$ in striatum and frontal cortex of aged rats, respectively. In parallel with the relative absence of effect on choline transport in hippocampus of aged rats, ${ }^{3} \mathrm{H}$-ACh synthesis was largely un- 


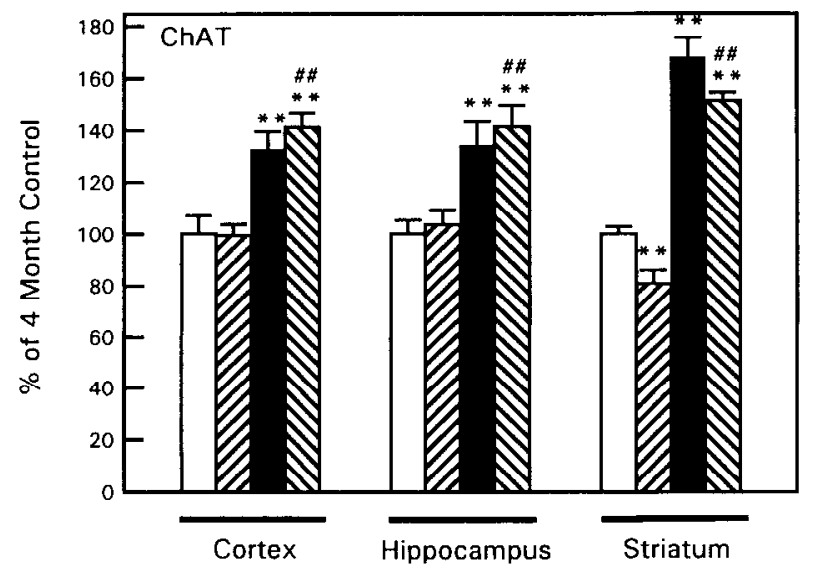

Figure 1. Effect of NGF treatment on ChAT activity in brain of young adult and aged Fischer-344 rats. Vehicle or NGF was administered continuously into right lateral ventricle of rats by osmotic minipump for 2 weeks before measurement of ChAT activity. Groups included 4-month-old control ( $\square, n=12$ ), 24-month-old control (區, $n=4$ ), 4-month-old NGF-treated $(\square, n=12$ ), and 24-month-old NGF-treated $(\mathbb{S}, n=4)$ animals. Data are the mean \pm SEM values in percentage change from values measured in 4-month-old vehicle-treated control group. Statistical significance of differences between groups was determined on data values before conversion to percentage of control group: **, $p \leq 0.01$ compared with 4 month controls; \#\#, $p \leq 0.01$ compared with 24 month controls.

changed by NGF treatment in this brain region when compared to age-matched controls.

The relative conversion of ${ }^{3} \mathrm{H}$-choline accumulated into nerve terminals to ${ }^{3} \mathrm{H}-\mathrm{ACh}$ was compared in young and aged rats. Whereas between $68 \%$ and $77 \%$ of accumulated ${ }^{3} \mathrm{H}$-choline was converted to ${ }^{3} \mathrm{H}-\mathrm{ACh}$ in the synaptosomes of all three brain regions from 4-month-old control rats, this same measure ranged from $55 \%$ to $76 \%$ in control aged rats. There did not appear to be differences between the three brain regions. Treatment of animals for 2 weeks with NGF did not alter the relative efficiency of synthesis of ACh, with $70-78 \%$ and $60-75 \%$ of ${ }^{3} \mathrm{H}$-choline becoming acetylated in 4- and 24-month-old rats, respectively. Again, there did not appear to be consistent interregion differences in either age group.

\section{Effect of NGF on the release of endogenous and newly synthesized ACh}

Release of endogenous ACh from brain slices of control and NGF-treated rats was measured using modifications of the chemiluminescent method of Israel and Lesbats (1982). A representative trace for release of $\mathrm{ACh}$ from striatal slices is shown in Figure 4. Chronic administration of NGF resulted in enhanced $\mathrm{ACh}$ release from slices of hippocampus and striatum of 4-month-old rats. ACh release from slices of all three brain areas of aged animals was also increased to values similar to young adult animals $(107 \pm 8 \%, 113 \pm 7 \%$, and $107 \pm 8 \%$ of 4 -month-old vehicle-treated controls) (Fig. 5). Relative to 24 month age-matched vehicle-treated controls, significant increases in endogenous $\mathrm{ACh}$ release were measured in hippocampus $(135 \pm 9 \%, P<0.01)$ and striatum $(146 \pm 11 \%, P<$ $0.01)$.

Basal and potassium-evoked release of newly synthesized ${ }^{3} \mathrm{H}$ ACh from synaptosomes was also measured. As illustrated in Figure 6, NGF treatment of young adult rats resulted in significantly increased basal ${ }^{3} \mathrm{H}$-ACh release from synaptosomes pre-

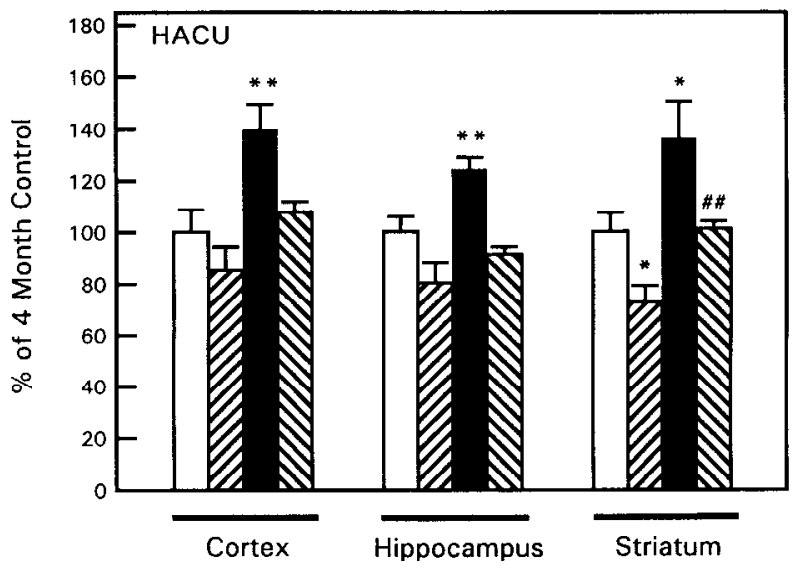

Figure 2. Effect of NGF treatment on high-affinity choline uptake in brain of young adult and aged Fischer-344 rats. Vehicle or NGF was administered continuously into right lateral ventricle of rats by osmotic minipump for 2 weeks before preparation of synaptosomes and measurement of hemicholinium-sensitive choline uptake activity. Groups included 4-month-old control ( $\square, n=8$ ), 24-month-old control (四, $n$ $=4)$, 4-month-old NGF-treated $(\square, n=8$ ), and 24-month-old NGFtreated $(\mathbb{\mathbb { N }}, n=4)$ animals. Data are mean \pm SEM values in percentage change from values measured for 4-month-old vehicle-treated control group. Statistical significance of differences between groups was determined on data values before conversion to percentage of control group: ${ }^{*}, p \leq 0.05$ compared with 4 month controls; ${ }^{* *}, p \leq 0.01$ compared with 4 month controls; \#\#, $p \leq 0.01$ compared with 24 month controls.

pared from hippocampus and striatum. In contrast, basal release of synaptosomal ${ }^{3} \mathrm{H}-\mathrm{ACh}$ release was not substantially altered by NGF administration in the aged rats; basal release remained significantly depressed compared to the young adult group.

Similar results were obtained for the effect of NGF on potassium-evoked ${ }^{3} \mathrm{H}$-ACh release (Fig. 7). NGF treatment of young

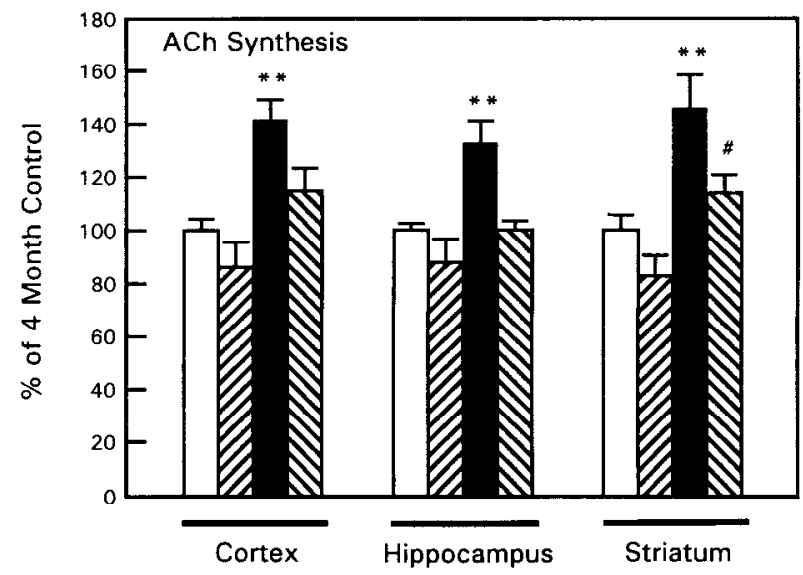

Figure 3. Effect of NGF treatment on ACh synthesis in brain of young adult and aged Fischer-344 rats. Vehicle or NGF was administered continuously into right lateral ventricle of rats by osmotic minipump for 2 weeks before preparation of synaptosomes and measurement of ${ }^{3} \mathrm{H}$-ACh synthesis from ${ }^{3} \mathrm{H}$-choline taken up into the nerve terminals. Groups included 4-month-old control $(\square, n=8)$, 24-month-old control (遂, $n=4$ ), 4-month-old NGF-treated (,$n=8$ ), and 24-month-old NGF-treated ( $n=4$ ) animals. Data are mean \pm SEM values in percentage change from values measured for 4-month-old vehicle-treated control group. Statistical significance of differences between groups was determined on data values before conversion to percentage of control group: ${ }^{* *}, p \leq 0.01$ compared with 4 month controls; $\#, p \leq 0.05$ compared with 24 month controls. 


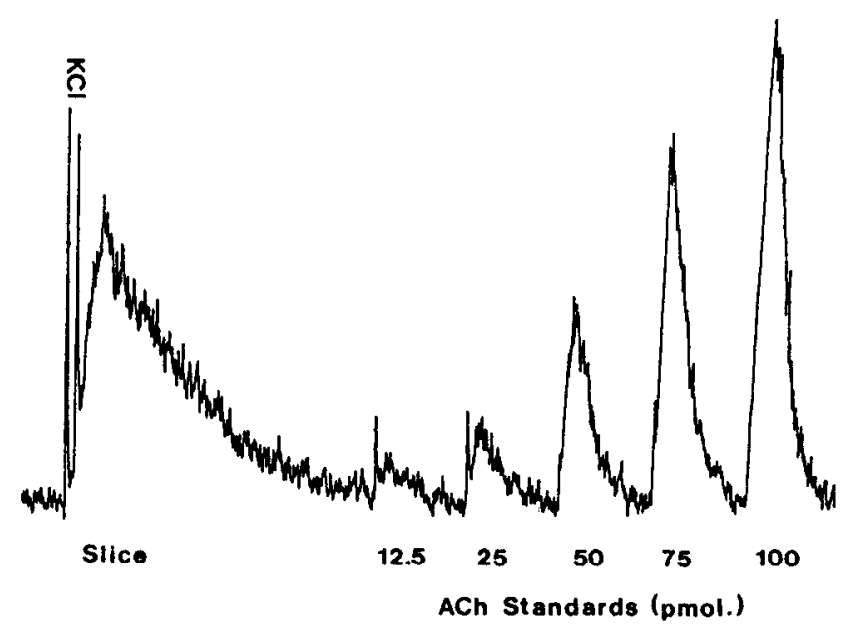

Figure 4. Profile of release of endogenous ACh from striatal slice of young adult Fischer-344 rats. Slice(s) were placed in darkened chambers in cuvettes containing reaction mixture (see Materials and Methods), and then $\mathrm{ACh}$ release was stimulated by the injection of $\mathrm{KCl}$. Light emission, representing sequential degradation of released $\mathrm{ACh}$ to choline and hydrogen peroxide, was recorded following detection and amplification of the signal. ACh release from each slice(s) was quantified by addition of standards of known amounts of $\mathrm{ACh}$, injected after the response due to endogenous release had returned toward baseline. The amplitude of the response for release from slice(s) was measured, and ACh release in picomoles was determined from a standard curve constructed from the response to standards.

adult animals resulted in significant increases in synaptosomal newly synthesized ${ }^{3} \mathrm{H}$-ACh release to about $140 \%$ of control in all three brain regions. In aged rats, NGF treatment also stimulated evoked ${ }^{3} \mathrm{H}$-ACh release, but the levels achieved were still only $40 \%$ of those measured in the young adult controls. Relative

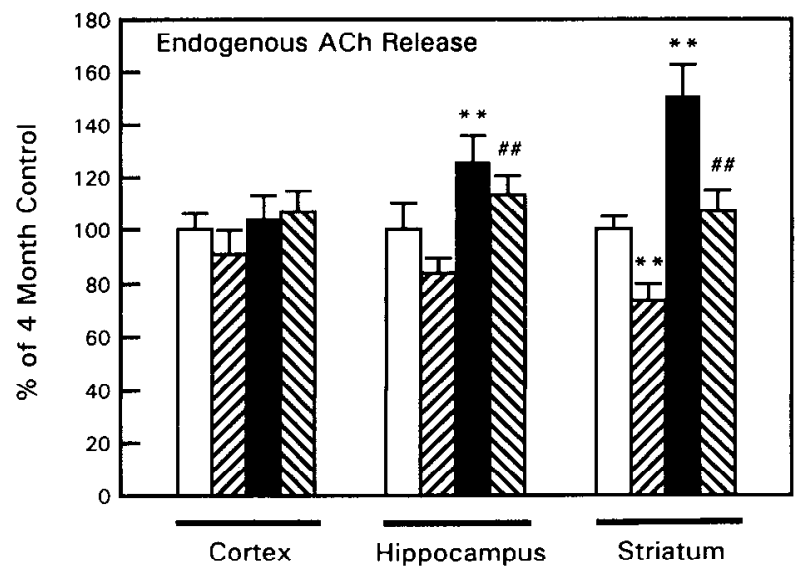

Figure 5. Effect of NGF treatment on release of endogenous ACh from brain slices of young adult and aged Fischer-344 rats. Vehicle or NGF was administered continuously into right lateral ventricle of rats by osmotic minipump for 2 weeks before preparation of brain slices and luminometric measurement of release of endogenous $A C h$ in response to potassium-induced depolarization. Groups included 4-month-old control ( $\square$, cortex $n=5$, hippocampus and striatum $n=6$ ), 24-month-

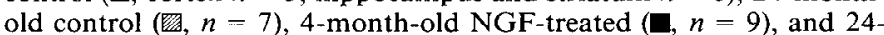
month-old NGF-treated ( $\mathbb{\mathbb { N }}$, cortex and hippocampus $n=8$, striatum $n=9$ ) animals. Data are mean \pm SEM values in percentage change from values measured for 4-month-old vehicle-treated control group. Statistical significance of differences between groups was determined on data values before conversion to percentage of control group: ${ }^{* *}, p \leq$ 0.01 compared with 4 month controls; \#\#, $p \leq 0.01$ compared with 24 month controls.

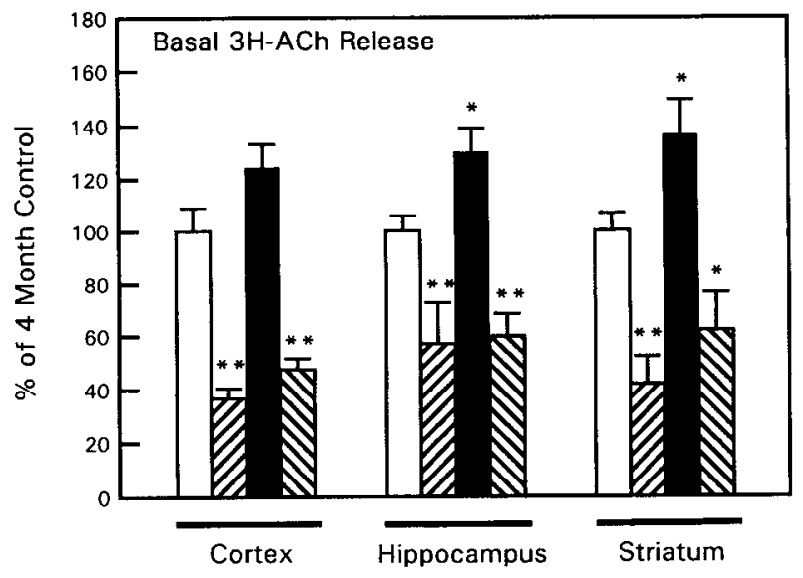

Figure 6. Effect of NGF treatment on basal release of newly synthesized ${ }^{3} \mathrm{H}-\mathrm{ACh}$ from synaptosomes of brain of young adult and aged Fischer-344 rats. Vehicle or NGF was administered continuously into right lateral ventricle of rats by osmotic minipump for 2 weeks before preparation of synaptosomes, formation of ${ }^{3} \mathrm{H}-\mathrm{ACh}$ from ${ }^{3} \mathrm{H}$-choline, and measurement of basal ${ }^{3} \mathrm{H}-\mathrm{ACh}$ release from the nerve terminals. Groups included 4-month-old control $(\square, n=8)$, 24-month-old control (湶, $n-4$ ), 4-month-old NGF-treated $(\square, n=8$ ), and 24-month-old NGF-treated ( $n=4)$ animals. Data are mean \pm SEM values in percentage change from values measured for 4-month-old vehicle-treated control group. Statistical significance of differences between groups was determined on data values before conversion to percentage of control group: ${ }^{*}, p \leq 0.05$ compared with 4 month controls; ${ }^{* *}, p \leq 0.01$ compared with 4 month controls.

to the 24 month age-matched controls, evoked ${ }^{3} \mathrm{I}-\mathrm{ACh}$ release was significantly increased in hippocampus $(136 \%, P<0.01)$ and striatum $(170 \%, P<0.001)$.

The relative proportions of newly synthesized ${ }^{3} \mathrm{H}-\mathrm{ACh}$ re-

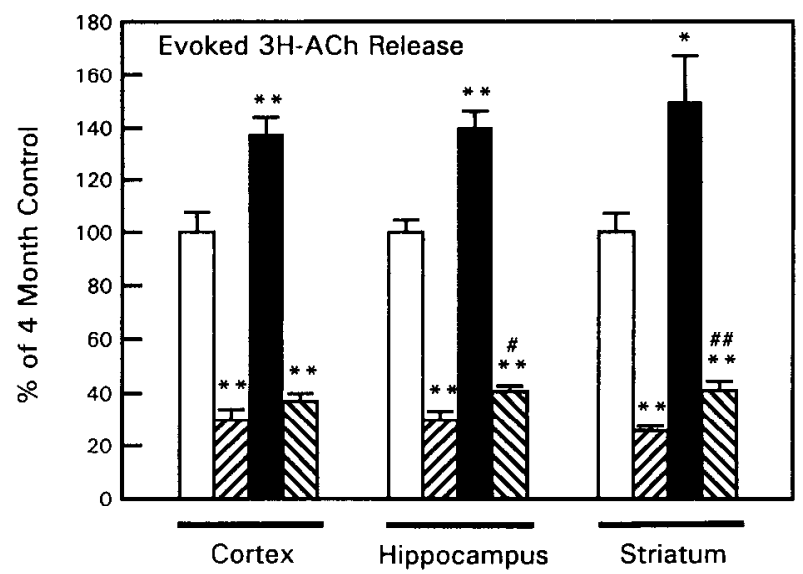

Figure 7. Effect of NGF treatment on potassium-evoked release of newly synthesized ${ }^{3} \mathrm{H}-\mathrm{ACh}$ from synaptosomes of brain of young adult and aged Fischer-344 rats. Vehicle or NGF was administered continuously into right lateral ventricle of rats by osmotic minipump for 2 weeks before preparation of synaptosomes, formation of ${ }^{3} \mathrm{H}-\mathrm{ACh}$ from ${ }^{3} \mathrm{H}$-choline, and measurement of depolarization-induced release of ${ }^{3} \mathrm{H}$ ACh from the nerve terminals. Groups included 4-month-old control

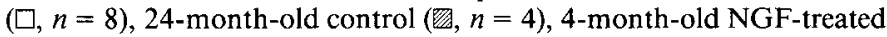

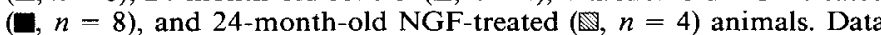
are mean \pm SEM values in percentage change from values measured for 4-month-old vehicle-treated control group. Statistical significance of differences between groups was determined on data values before conversion to percentage of control group: ${ }^{*}, p \leq 0.05$ compared with 4 month controls; ${ }^{* *}, p \leq 0.01$ compared with 4 month controls; \#, $p$ $\leq 0.05$ compared with 24 month controls; \#\#, $p \leq 0.01$ compared with 24 month controls. 
Table 2. Fractional release of newly synthesized ${ }^{3} \mathrm{H}-\mathrm{ACh}$ in control and NGF-treated rats

\begin{tabular}{|c|c|c|c|c|c|c|c|}
\hline \multirow[b]{2}{*}{ Age group } & \multirow[b]{2}{*}{ Treatment } & \multicolumn{2}{|l|}{ Cortex } & \multicolumn{2}{|c|}{ Hippocampus } & \multicolumn{2}{|l|}{ Striatum } \\
\hline & & Basal & Evoked & Basal & Evoked & Basal & Evoked \\
\hline \multirow[t]{2}{*}{4 month } & Control & $1.99 \pm 0.16$ & $6.96 \pm 0.29$ & $1.71 \pm 0.07$ & $6.55 \pm 0.17$ & $2.71 \pm 0.11^{*}$ & $5.32 \pm 0.15 \#$ \\
\hline & NGF & $1.82 \pm 0.08$ & $7.12 \pm 0.11$ & $1.60 \pm 0.07$ & $6.61 \pm 0.12$ & $2.69 \pm 0.09 \#$ & $5.77 \pm 0.24 \#$ \\
\hline \multirow[t]{2}{*}{24 month } & Control & $0.87 \pm 0.16$ & $2.04 \pm 0.27$ & $0.96 \pm 0.26$ & $1.92 \pm 0.20$ & $1.12+0.32$ & $1.34+0.18$ \\
\hline & NGF & $0.68 \pm 0.07$ & $1.84 \pm 0.16$ & $0.83 \pm 0.12$ & $2.20 \pm 0.26$ & $1.11 \pm 0.32$ & $1.63 \pm 0.27$ \\
\hline
\end{tabular}

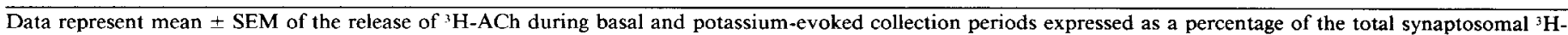

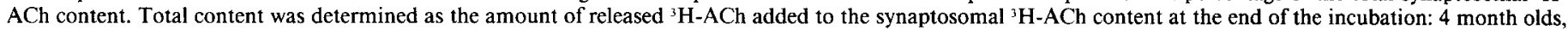

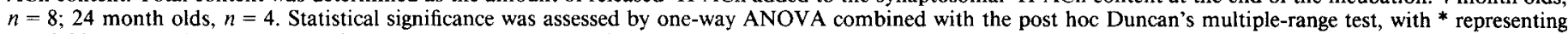
$p \leq 0.05$ compared to cortex and hippocampus and \# representing $p \leq 0.01$ compared to cortex and hippocampus.

leased during both resting and depolarized test periods was evaluated. Several interesting features emerged, as shown in Table 2. First, NGF treatment did not alter proportional basal or potassium-evoked ${ }^{3} \mathrm{H}$-ACh release within any of the three brain regions in either age group when compared with vehicle-treated controls. Second, in aged animals there were significant decreases in the fraction of newly synthesized ${ }^{3} \mathrm{H}$-ACh that was relcased during both basal and potassium-evoked test periods in all three brain regions compared with young adult controls. Third, in 4-month-old control animals the dynamics of release of transmitter appeared to be different in striatal synaptosomes than in either frontal cortex or hippocampus, with a significantly larger fraction of ${ }^{3} \mathrm{H}-\mathrm{ACh}$ being released in striatum under resting conditions $(2.71 \pm 0.11$ compared to either $1.99 \pm 0.16, P<$ 0.05 , or $1.71 \pm 0.07, P<0.01)$ and a significantly smaller proportion being released under depolarized conditions $(5.32$ \pm 0.15 compared to $6.96 \pm 0.29$ or $6.55 \pm 0.17, P<0.01$ ). The same relationship was observed in 24-month-old animals, although statistically significant differences were not obtained. ${ }^{3} \mathrm{H}-\mathrm{ACh}$ released by potassium depolarization was elevated about 4-fold over basal release in cortex and hippocampus of young adult rats (3.5- and 3.9-fold in cortex and 3.8- and 4.1-fold in hippocampus of control and NGF-trcated rats, respectively). This is compared to a 2-fold depolarization-induced increase in ${ }^{3} \mathrm{H}-\mathrm{ACh}$ release in striatum $(2.0$ - and 2.1 -fold increase over basal release in control and NGF-treated rats, respectively). Smaller depolarization-induced increases relative to basal release were observed in 24-month-old rats with approximately 2-3-fold increases in cortex and hippocampus (2.3- and 2.7fold in cortex and 2.0- and 2.7-fold in hippocampus in control and NGF-treated rats, respectively) and about 1.5-fold increases in striatum (1.2- and 1.5-fold in control and NGF-treated rats, respectively).

Regression analysis was performed to determine whether there was a relationship between $\mathrm{ACh}$ synthesis and depolarizationevoked ${ }^{3} \mathrm{H}-\mathrm{ACh}$ release, with the magnitude of the NGF-induced increase in $\mathrm{ACh}$ release correlating with the increase in synthesis. This appeared to be the case in the NGF-treated young adult group, with correlation coefficients in frontal cortex, hippocampus, and striatum of $0.793,0.704$, and 0.966 , respectively; graphically, the regression lines were significantly different from zero $(P<0.02, P=0.05$, and $P<0.0001$, respectively). This relationship, however, did not exist in the NGF-treated aged group. Correlation coefficients relating ACh synthesis and evoked release of ${ }^{3} \mathrm{H}-\mathrm{ACh}$ were found to be $-0.941,-0.098$, and 0.948 (frontal cortex, hippocampus, and striatum, respectively), with none of the regression lines significantly different from zero.

\section{Content of $A C h$}

As the velocity of synaptosomal high-affinity choline uptake and $\mathrm{ACh}$ synthesis may vary as a function of ACh levels in synaptosomes (Jenden et al., 1976), we measured ACh content in synaptosomes in samples taken at the beginning of each experiment. In addition, we hoped that this measurc would provide some information about the effect of NGF on steady-state ACh levels in brain. As shown in Table 3, in both 4- and 24month-old groups synaptosomal $\mathrm{ACh}$ levels in all three brain regions of NGF-treated rats were essentially the same as control animals. Additionally, there did not appear to be age-related changes in $\mathrm{ACh}$ content in any of the brain regions studied.

In a separate experiment, we measured ACh levels in brains of a group of 4-month-old rats treated for 2 weeks with NGF or vehicle, and then killed by head-focused microwave. ACh content in basal forebrain of control animals was $91.0 \pm 7.1$ ( $n$ $=4)$ compared to $97.8 \pm 3.6(n=3) \mathrm{pmol} / \mathrm{mg}$ tissue in the NGF-treated group, and $107.4 \pm 7.4(n=3)$ in striatum of control animals compared to $116.6 \pm 9.6(n=3) \mathrm{pmol} / \mathrm{mg}$ tissue in NGF-treated rats. Thus, it is clear that chronic NGF administration had little effect on brain $\mathrm{ACh}$ levels in the regions examincd.

\section{Discussion}

Several new observations were made in the present study concerning the effects of chronic intracerebral administration of NGF on cholinergic neuron function in basal forebrain and striatum of adult and aged Fischer-344 rats: (1) ACh synthesis was increased by NGF in both 4 - and 24 -month-old rats in the three brain regions examined, with the exception of hippocampus in the aged group; (2) NGF treatment did not appear to alter the relative efficiency of synthesis of $\mathrm{ACh}$ within the nerve terminal, as indicated by comparable conversion of accumulated ${ }^{3} \mathrm{H}$-choline to ${ }^{3} \mathrm{H}$-ACh relative to controls; (3) endogenous

Table 3. Synaptosomal ACh content in control and NGF-treated rats

\begin{tabular}{cllll} 
Age group & Treatment & $\begin{array}{l}\text { Frontal } \\
\text { cortex }\end{array}$ & Hippocampus & Striatum \\
\hline 4 month & Control & $367 \pm 20$ & $577 \pm 26$ & $1073 \pm 96$ \\
& NGF & $442 \pm 56$ & $588 \pm 65$ & $1303 \pm 101$ \\
24 month & Control & $404 \pm 31$ & $656 \pm 40$ & $961 \pm 68$ \\
& NGF & $382 \pm 12$ & $532 \pm 32$ & $1068 \pm 64$
\end{tabular}

Data are expressed as mean \pm SEM in pmol $\mathrm{ACh} / \mathrm{mg}$ protein: 4 month olds, $n=8 ; 24$ month olds, $n=4$. 
ACh release was enhanced by NGF treatment in slices from hippocampus and striatum, but not frontal cortex in both adult and aged rats; (4) basal and depolarization-induced release of newly synthesized ${ }^{3} \mathrm{H}-\mathrm{AC} h$ was increased by NGF treatment of young adult rats in all three brain regions, but in the aged rats, only potassium-evoked release of transmitter from hippocampus and striatum was affected by NGF treatment; and (5) ACh content in either brain tissue or freshly prepared synaptosomal fractions was not affected by NGF administration.

An important feature emerging from the present study is the apparent differential responsiveness of CNS cholinergic neurons in aged compared to the young adult rats to chronic intracerebral administration of NGF. In the young adult brain, all cholinergic functional parameters measured were increased by NGF infusion with the greatest effect generally in the striatum. However, a less uniform response of striatal and basal forebrain cholinergic neurons was apparent in the aged animal. Again, as observed in the young adult, increases in cholinergic markers were generally greatest in striatum in the aged rat brain, with effects of NGF on projection areas of basal forebrain cholinergic neurons being less consistent. For example, high-affinity choline transport and $\mathrm{ACh}$ synthesis were not altered in hippocampus of the aged rat brain after 2 weeks NGF administration, but ChAT, depolarization-induced release of ${ }^{3} \mathrm{H}-\mathrm{ACh}$, and endogenous $\mathrm{ACh}$ were enhanced. Conversely, high-affinity choline uptake and ChAT and ACh synthesis were increased in frontal cortex of aged rat brain, but there was no change compared to age-matched controls in depolarization-induced release of either endogenous or newly synthesized ${ }^{3} \mathrm{H}-\mathrm{ACh}$ release. These data, in conjunction with the regional differences in age-related decreases in cholinergic measures (Table 1), indicate that the regulation of cholinergic neurotransmission and sensitivity to exogenous NGF may be regionally specific; that is, the effects of age and NGF on interneurons of the striatum are different from those on the projection neurons in the medial septum, and different from those of the nucleus basalis magnocellularis (Williams, 1991).

It is predicted that the increases in $\mathrm{ACh}$ synthesis and release measured in the present study after 2 weeks NGF administration may not be maximal, particularly in the young adult group. This is based, in part, upon our previous observations that continuation of growth factor treatment until 4 weeks resulted in further increases in choline uptake and ChAT activity (Williams and Rylett, 1990), and is supported by recent studies reported by Lapchak and Hefti (1991) that extension of NGF treatment in partial fimbrial-transected young rats from 3 to 9 weeks resulted in enhanced survival of denervated septohippocampal cholinergic neurons, as demonstrated by greater ${ }^{3} \mathrm{H}-\mathrm{ACh}$ synthesis by remaining neurons. It is also interesting to note that in the study of Lapchak and Hefti (1991) no change in ${ }^{3} \mathrm{H}-\mathrm{ACh}$ synthesis or release was observed from hippocampus of the contralateral unlesioned hemisphere of NGF-treated young rats when compared to cytochrome c-treated controls. This contrasts with the significant enhancement in a variety of measures of cholinergic neuron function in unlesioned, presumably normal, frontal cortex, hippocampus, and striatum of both young adult and aged rat brain observed in the present study. Although the reason for this difference is unclear, one possible explanation could be the use of different strains of rats (Williams and Oostveen, 1992).

ACh content of brain tissue and freshly prepared synaptosomes from NGF-treated rats did not differ from that of control rats, suggesting that enhanced transmitter synthesis was bal- anced by enhanced release. This is in contrast to the findings of Kewitz et al. (1990), in which ACh concentration in brain of neonatal rats was significantly and transiently (about $24 \mathrm{hr}$ ) elevated within $48 \mathrm{hr}$ following a single high-dose intracerebral injection of NGF. While the difference in these results could relate to different doses of NGF administered in the two studies, it could also represent an age-related effect of NGF that is present in the newborn, but not adult or aged, nervous system. Further studies are required to clarify this point.

Modulation of release of neurotransmitter is one of the most important parameters in terms of changing net communication of information to target cells; hence, a primary objective in the present study was to monitor alterations in ACh release by NGF. NGF administration in the young adult group increased release of both endogenous stores and newly synthesized pools of $\mathrm{ACh}$, with a significant correlation between enhanced ACh synthesis and enhanced depolarization-evoked release of ${ }^{3} \mathrm{H}-\mathrm{ACh}$ in all three brain regions. This latter relationship appears not to exist in the aged group, indicating that NGF-induced effects on release of newly synthesized $\mathrm{ACh}$ were not coupled to transmitter synthesis; the largest increases in ${ }^{3} \mathrm{H}-\mathrm{ACh}$ release were not observed mainly in animals with the highest increases in ACh synthesis. Similarly, release of both endogenous ACh (Fig. 5) and newly synthesized ${ }^{3} \mathrm{H}$-ACh (Fig. 7) was significantly increased from hippocampus of NGF-treated aged rats in the absence of significant changes in transmitter synthesis (Fig. 3). This latter effect, however, did not result in a significant change in the fractional release of ${ }^{3} \mathrm{H}-\mathrm{ACh}(2.20 \%$ in NGF-treated rats compared to $1.92 \%$ in the control group), suggesting that mobilization of transmitter was not altered by the growth factor. The effects of NGF on ACh release in the aged brain appear complex. The magnitude of the age-related decrease of ACh was not as great for the measurement of endogenous transmitter, and NGF treatment restored this parameter to the level observed in the young adult control group. In contrast, both basal and depolarization-induced ${ }^{3} \mathrm{H}-\mathrm{ACh}$ release were markedly reduced in the aged group, and NGF administration, although leading to significant cnhancement of these mcasures in somc brain arcas, did not restore transmitter release to levels found in the younger control animals.

The mechanisms underlying the large decreases in ACh release in CNS cholinergic neurons of aged animals have not been elucidated. In general, measurement of $\mathrm{ACh}$ release from either brain slices or synaptosomes reveals substantially decreased transmitter release in aged animals (for review, see Decker, 1987). It is interesting that this decreased transmitter release occurs in the absence of age-related changes in neuronal $\mathrm{ACh}$ content (Sherman et al., 1981; see review by Giacobini, 1988), leading to the suggestion that the mechanisms controlling neuronal $\mathrm{ACh}$ levels remain functional during the aging process (Kindel and Karczmar, 1981, 1982); in aged mouse brain, the turnover rate for $\mathrm{ACh}$ is decreased by about $30 \%$ (Kindel and Karczmar, 1982). It is probable that alterations in the mechanisms controlling the mobilization and release of ACh (cf. Collier, 1977; Prado et al., 1992) rather than deficits in ACh synthesis or content cause the observed age-related impairments of motor and cognitive performance of aged rats in various behavioral paradigms (Olton, 1990; Williams et al., 1993). Meyer et al. (1986) reported evidence indicating that the age-related decrease in $\mathrm{ACh}$ release may be in part the result of decreased capacity of calcium to trigger transmitter release in aged nerve terminals. However, other studies have reported that both resting and 
potassium-stimulated levels of neuronal cytosolic free calcium were unaffected by aging in Fischer-344 rats (Farrar et al., 1989).

In summary, chronic NGF administration to both young and aged rats resulted in stimulation of $\mathrm{ACh}$ release. Although NGF treatment in the aged rat did not restore the depolarizationevoked release of newly synthesized ${ }^{3} \mathrm{H}-\mathrm{ACh}$ to the young adult control levels, there were significant increases in release of newly synthesized $\mathrm{ACh}$ from hippocampus and striatum of aged animals when compared to the 24 month age-matched controls. This enhanced release of transmitter by NGF may underlie the alterations in behavior (both positive and negative) observed in NGF-treated aged rats (Fischer, 1987; Williams et al., 1993).

\section{References}

Appel SH (1981) A unifying hypothesis for the cause of amyotrophic lateral sclerosis, parkinsonism and Alzheimer's disease. Ann Neurol 10:499-505.

Collier B (1977) Biochemistry and physiology of cholinergic transmission. In: Handbook of physiology - the nervous system I (Kandel ER, Brookhart JM, Mountcastle VB, Geiger SR, eds), pp 463-483. Baltimore: Waverly.

Decker MW (1987) The effect of aging on hippocampal and cortical projections of the basal forebrain cholinergic system. Brain Res Rev $12: 423-438$.

Farrar RP, Rezazadeh SM, Morris JL, Dildy JE, Gnau K, Leslie SW (1989) Aging does not alter cytosolic calcium levels of cortical synaptosomes in Fischer 344 rats. Neurosci Lett 100:319-325.

Fischer W, Wictorin K, Bjorklund A, Williams LR, Varon S, Gage FH (1987) Amelioration of cholinergic neuron atrophy and spatial memory impairment in aged rats by nerve growth factor. Nature 329:6568.

Fonnum F (1969) Radiochemical microassays for the determination of choline acetyltransferase and acetylcholinesterase activities. Biochem J 115:465-472.

Giacobini E (1988) The cholinergic system in aging. Handb Exp Pharmacol 86:665-695.

Gnahn H, Hefti F, Heumann R, Schwab ME, Thoenen H (1983) NGFmediated increases in choline acetyltransferase (ChAT) in the neonatal rat forebrain: evidence for a physiological role of NGF in brain? Dev Brain Res 9:45-52.

Goldberg AM, McCaman RE (1975) The determination of picomole amounts of acetylcholine in mammalian brain. J Neurochem 20:1-8.

Gray EG, Whittaker VP (1962) The isolation of nerve endings from brain: an electron microscopic study of cell fragments derived by homogenization and centrifugation. J Anat 96:79-87.

Hagg T, Manthorpe M, Vahlsing HL, Varon S (1988) Delayed treatment with nerve growth factor reverses the apparent loss of cholinergic neurons after acute brain damage. Exp Neurol 101:303-312.

Hefti $F$ (1986) Nerve growth factor (NGF) promotes survival of septal cholinergic neurons after fimbrial transection. J Neurosci 6:21552162.

Hefti F, Weiner WJ (1986) Nerve growth factor and Alzheimer's disease. Ann Neurol 20:275-281.

Hefti F, Hartikka J, Eckenstein F, Gnahn H, Heumann R, Schwab ME (1985) Nerve growth factor increases choline acetyltransferase but not survival of fiber outgrowth of cultured fetal septal cholinergic neurons. Neuroscience 14:55-68.

Hcfti F, Hartikka J, Knusel B (1989) Function of neurotrophic factors in the adult and ageing brain and their possible use in the treatment of neurodegenerative diseases. Neurobiol Aging 10:515-533.

Honnegar P, Lenoir D (1982) Nerve growth factor (NGF) stimulation of cholinergic telencephalic neurons in aggregating cell cultures. Dev Brain Res 3:229-238.

Israel M, Lesbats B (1982) Application to mammalian tissues of the chemiluminescent method for detecting acetylcholine. J Neurochem 39:248-250.

Jenden DJ, Jope RS, Weiler MH (1976) Regulation of acetylcholine synthesis: does cytoplasmic acetylcholine concentration control high affinity choline uptake? Science 194:635-637.

Jope RS (1979) High affinity choline transport and acetyl-CoA pro- duction in brain and their roles in the regulation of acetylcholine synthesis. Brain Res Rev 1:313-344.

Kewitz H, Rost KL, Pleul O, Handke A (1990) Dose-related effects of nerve growth factor (NGF) on choline acetyltransferase (ChAT), acetylcholine $(\mathrm{ACh})$ content and $\mathrm{ACh}$ turnover in the brain of newborn rats. Neurochem Int 17:239-244.

Kindel GH, Karczmar AG (1981) Effect of single and repeatcd choline administration on brain choline, acetylcholine and acetylcholine turnover of CF-1 mice. Fed Proc 40:269.

Kindel GH, Karczmar AG (1982) Effect of choline administration on brain choline and acetylcholine levels and acetylcholine turnover of young and old mice. Fed Proc 41:1323.

Lapchak PA, Hefti F (1991) Effect of recombinant human nerve growth factor on presynaptic cholinergic function in rat hippocampal slices following partial septohippocampal lesions: measures of $\left[{ }^{3} \mathrm{H}\right]$ acetylcholine synthesis, $\left[{ }^{3} \mathrm{H}\right]$ acetylcholine release and choline acetyltransferase activity. Neuroscience 42:639-649.

Lapchak PA, Knüsel B, Hefti F (1993) Pharmacology of NGF in the brain. Adv Pharmacol, in press.

Levi-Montalcini R (1982) Developmental neurobiology and the natural history of nerve growth factor. Annu Rev Ncurosci 5:341-362.

Lowry OH, Rosebrough NJ, Farr AL, Randall RJ (1951) Protein measurement with the Folin phenol reagent. J Biol Chem 193:265275.

Meyer EM, Crews FT, Otero DH, Larsen K (1986) Aging decreases the sensitivity of rat cortical synaptosomes to calcium ionophoreinduced acetylcholine release. J Neurochem 47:1244-1246.

Mobley WC, Rutkowski JL, Tennekoon GI, Buchanan K, Johnston MV (1985) Choline acetyltransferase activity in striatum of neonatal rats increased by nerve growth factor. Science 229:284-286.

Prado MA, Gomez MV, Collier B (1992) Mobilization of the readily releasable pool of acetylcholine from a sympathetic ganglion by tityustoxin in the presence of vesamicol. J Neurochem 59:544-552.

Olton DS (1990) Dementia: animal models of the cognitive impairments following damage to the basal forcbrain cholinergic system. Brain Res Bull 25:499-502.

Sherman KA, Huster JE, Dean RL, Bartus RT, Friedman E (1981) Presynaptic cholinergic mechanisms in brain of aged rats with memory impairments. Neurobiol Aging 2:99-104.

Takei N, Tsukui H, Hatanaka H (1988) Nerve growth factor increases the intracellular content of acetylcholine in cultured septal neurons from developing rats. J Neurochem 51:1118-1125.

Takei N, Tsukui H, Hatanaka H (1989) Intracellular storage and evoked release of acetylcholine from postnatal rat basal forebrain cholinergic neurons in culture with nerve growth factor. J Neurochem 53:14051410 .

Whittemore SR, Seiger A (1987) The expression, localization and functional significance of $\beta$-nerve growth factor in the central nervous system. Brain Res Rcv 12:439-464.

Williams LR (1991) Exogenous nerve growth stimulates choline acetyltransferase activity in aging Fischer 344 male rats. Neurobiol Aging $12: 39-46$.

Williams LR, Rylett RJ (1990) Exogenous nerve growth factor increases the activity of high-affinity choline uptake and choline acetyltransferase in brain of Fisher 344 male rats. J Neurochem 55:10421049.

Williams LR, Oostveen JA (1992) Sensitivity of Fischer $344 \times$ Brown Norway hybrid rats to exogenous NGF: weight loss correlates with stimulation of striatal choline acetyltransferase. Neurosci Lett 147 : $136-138$.

Williams LR, Varon S, Peterson GM, Wictorin K, Fischer W, Bjorklund A, Gage FH (1986) Continuous infusion of nerve growth factor prevents basal forebrain neuronal death after fimbria fornix transection. Proc Natl Acad Sci USA 83:9231-9235.

Williams LR, Vahlsing HL, Lindamood T, Gage FH, Varon S, Manthorpe $M$ (1987) A small gauge cannula device for continuous infusion of exogenous agents into the brain. Exp Neurol 95:743-754.

Williams LR, Jodelis KS, Donald MR (1989) Axotomy-dependent stimulation of choline acetyltransferase by exogenous mouse nerve growth factor in rat basal forebrain. Brain Res 498:243-256.

Williams LR, Rylett JR, Ingram DK, Joseph JA, Moises HC, Tang AH, Mervis RF (1993) NGF affects the cholinergic neurochemistry and behavior of aged rats. Prog Brain Res 98:251-256.

Yamamura HI, Snyder SH (1973) High affinity choline transport of choline into synaptosomes of rat brain. J Neurochem 21:1355-1374. 